\title{
Use of loteprednol for routine prophylaxis after photorefractive keratectomy
}

This article was published in the following Dove Press journal:

Clinical Ophthalmology

30 April 2012

Number of times this article has been viewed

Mark D Mifflin'

Lisa L Leishman'

Steven M Christiansen'

Shameema Sikder ${ }^{2}$

Maylon Hsu'

Majid Moshirfar'

'Department of Ophthalmology, John A Moran Eye Center, University of Utah School of Medicine, Salt Lake City, UT, ${ }^{2}$ Wilmer Eye Institute, Johns Hopkins Hospital, Johns Hopkins University, Baltimore, MD, USA
Correspondence: Mark Mifflin John A Moran Eye Center, 65 Mario Capecchi Drive, Salt Lake City,

UT 84I32, USA

Tel + I 80I 5857689

Fax + I 8019479286

Email mark.mifflin@hsc.utah.edu
Background: The purpose of this work is to report our experience using loteprednol $0.5 \%$ for routine prophylaxis after photorefractive keratectomy in an academic refractive surgery center.

Materials and methods: Photorefractive keratectomy was performed on 579 eyes from 316 patients in this retrospective chart review of patients treated postoperatively with either fluorometholone $0.1 \%$ (273 eyes) or loteprednol $0.5 \%$ (306 eyes). Primary outcome measures at 6 months included uncorrected distance visual acuity, corrected distance visual acuity, and manifest refraction spherical equivalent. Secondary outcome measures were incidence of corneal haze and increased intraocular pressure.

Results: There were no statistically significant differences in preoperative characteristics between the two groups when comparing age, sex, best-corrected visual acuity, spherical equivalent, or keratometry. Both groups achieved excellent visual outcomes, with a mean uncorrected distance visual acuity $(\log$ MAR $)$ of $0.004 \pm 1.4$ in the fluorometholone group and $-0.028 \pm 1.1$ in the loteprednol group $(P=0.013)$ at 6 months. Postoperative corneal haze and increased intraocular pressure were uncommon and not statistically different between the groups.

Conclusion: Loteprednol $0.5 \%$ performed similarly to fluorometholone $0.1 \%$ when used for prophylaxis following photorefractive keratectomy. The incidence of haze and increased intraocular pressure were similar between the two groups.

Keywords: loteprednol, fluorometholone, photorefractive keratectomy

\section{Introduction}

Excimer laser photoablation sculpts corneal tissue to correct refractive error during photorefractive keratectomy. Corneal haze is a well known and potentially visionthreatening complication of photorefractive keratectomy. Topical ophthalmic corticosteroids are routinely prescribed postoperatively by most surgeons to prevent this complication, but these medications may pose other risks, such as elevated intraocular pressure and cataract formation. The benefit of using topical corticosteroids to prevent haze is controversial, ${ }^{1,2}$ but some studies have demonstrated a decreased incidence of haze with corticosteroid use..$^{3,4}$

Desirable characteristics for prophylactic topical steroids to be used in photorefractive keratectomy include effective modulation of the healing response to prevent corneal haze while at the same time minimizing side effects, such as elevated intraocular pressure or cataract formation. Loteprednol etabonate is a corticosteroid that exerts its therapeutic effects and is then quickly changed into inactive metabolites by nonspecific esterases found in the cornea..$^{5}$ The faster metabolism of loteprednol 
is believed to give it a lower side effect profile than other steroids, having a smaller effect on intraocular pressure. ${ }^{6,7}$ This retrospective study compares outcomes of loteprednol $0.5 \%$ versus fluorometholone $0.1 \%$ used postoperatively in patients undergoing photorefractive keratectomy.

\section{Materials and methods}

Institutional review board approval was obtained and a retrospective chart review of patients who received photorefractive keratectomy surgery at the Moran Eye Center between January 2005 and May 2010 was performed. Complete 6-month follow-up data were available for 579 eyes from 316 patients. Two surgeons (MDM, MM) performed the photorefractive keratectomy surgery and the patients were divided into two groups depending on the postoperative steroid medications used, ie, loteprednol $0.5 \%$ (MDM) or fluorometholone $0.1 \%(\mathrm{MM})$. Patients with monovision refractive targets $(\geq-1.0 \mathrm{D})$ were excluded from postoperative visual outcome calculations.

\section{Surgical technique}

Patients with significant lens opacities, keratoconus, unstable refraction, autoimmune disease, pregnancy or breastfeeding, or immunosuppressive therapy were excluded from treatment. Photorefractive keratectomy was performed in the following manner. The corneal epithelium was gently debrided after exposure to ethanol $20 \%$ for $30-40$ seconds. Laser ablation was performed using the VISX Star S4 excimer laser (VISX Incorporated, Santa Clara, CA) and treatments were conventional or CustomVue ${ }^{\mathrm{TM}}$. Immediately after ablation, the ocular surface was rinsed with chilled saline for 30 seconds. This was followed by one drop of a topical fluoroquinolone, a topical nonsteroidal anti-inflammatory drug, prednisolone acetate $1 \%$, and a soft bandage contact lens. One hundred and sixty of the 579 eyes received a pledget soaked in mitomycin C $0.02 \%$ for 10-12 seconds after the laser ablation and before the balanced salt solution rinse.

\section{Postoperative management}

Patients were treated with a topical fluoroquinolone and prednisolone acetate $1 \%$ four times a day for one week, after which the regimens differed between the groups according to surgeon preference. Patients in the loteprednol $0.5 \%$ group were treated with prednisolone acetate $1 \%$ two times a day for three weeks followed by loteprednol $0.5 \%$ twice daily for one month and then daily for one month. Patients in the fluorometholone $0.1 \%$ group were treated with prednisolone acetate $1 \%$ four times a day for one month followed by fluorometholone $0.1 \%$ three times a day for a month, tapered by one drop a month.

Preoperative characteristics, including sex, age, manifest refraction spherical equivalent (MRSE), and postoperative outcomes, including uncorrected and corrected distance visual acuity, corneal haze, and elevated intraocular pressure, were compared between the two groups during the first 6 months after surgery. Significantly elevated postoperative intraocular pressure was defined as $\geq 25 \mathrm{mmHg}$ or as $\geq 10 \mathrm{mmHg}$ above preoperative intraocular pressure. Corneal haze was graded using the Fantes scale for which grade $0=$ clear, grade $0.5=$ trace opacity only seen by indirect broad illumination, grade $1=$ minimal density seen with difficulty with direct and diffuse illumination, grade $2=$ mild haze visible with direct focal slit illumination, grade 3 = moderately dense opacity that partially obscures iris detail, and grade $4=$ severely dense opacity that obscures intraocular structures. Statistical analysis was performed using parametric tests for numerical data and nonparametric tests for ordinal data.

\section{Results}

The fluorometholone group consisted of 273 eyes from 70 (47.0\%) males and $79(53.0 \%)$ females. The loteprednol group consisted of 306 eyes from 80 (47.9\%) males and 87 $(52.1 \%)$ females. The mean age was 35.5 (21-64) years and 34.7 (21-59) years in the fluorometholone and loteprednol groups, respectively $(P=0.271)$. Mean preoperative MRSE was $-4.03 \mathrm{D} \pm 1.92$ (range -10.38 to +4.63 ) and -4.09 $\mathrm{D} \pm 1.97$ (range -10.00 to +0.85 ) in the fluorometholone and loteprednol groups, respectively $(P=0.708$, Table 1$)$.

\section{Haze}

The fluorometholone group had 89 eyes (mean preoperative MRSE $-5.65 \mathrm{D} \pm 1.72$ ) treated with intraoperative mitomycin $\mathrm{C}$ and the loteprednol group had 50 eyes (mean preoperative MRSE $-5.85 \mathrm{D} \pm 2.90, P=0.616)$ treated with intraoperative mitomycin C. Figure 1 and Table 2 show the corneal haze outcomes on postoperative visits at months $1,2,3$, and 6 . For the purposes of our study, we defined post-photorefractive keratectomy corneal haze as being visually significant if it was associated with decreased visual acuity or subjective complaints by the patient. None of the eyes in the loteprednol group had visually significant haze at 6 months. In the fluorometholone group at 6 months, only two eyes (from one patient) had visually significant haze. The patient had a preoperative MRSE of $-5.75 \mathrm{D}$ OD and $-6.00 \mathrm{D}$ OS. The patient was treated with intraoperative mitomycin $\mathrm{C}$ but was reported to be noncompliant with postoperative medication and follow-up visits. The other eyes in the fluorometholone 
Table I Demographic and preoperative characteristics

\begin{tabular}{|c|c|c|c|}
\hline Demographics & Fluorometholone & Loteprednol & \\
\hline Patients (n) & 149 & 167 & \\
\hline Eyes (n) & 273 & 306 & \\
\hline Male:female & I:I & $\mathrm{I}: \mathrm{I}$ & \\
\hline Preoperative characteristics & Mean \pm SD (range) & Mean \pm SD (range) & $P$-value \\
\hline Age (y) & $35.5 \pm 9.3(21$ to 64$)$ & $34.7 \pm 8.2(21$ to 59$)$ & $0.27 I$ \\
\hline MRSE (D) & $-4.03 \pm 1.92(-10.38$ to 4.63$)$ & $-4.09 \pm 1.97(-9.25$ to 0.85$)$ & 0.708 \\
\hline Sphere (D) & $-4.52 \pm 1.95(-11.75$ to 4.00$)$ & $-4.52 \pm 2.03(-10.00$ to 0.85$)$ & 0.988 \\
\hline Cylinder (D) & $1.00 \pm 0.91(0.00$ to 5.00$)$ & $0.90 \pm 0.81(0.00$ to 4.00$)$ & 0.173 \\
\hline Keratometry (D) & $41.12 \pm 1.69(38.20$ to 47.94$)$ & $44.36 \pm 1.43(40.3 I$ to $48.8 I)$ & 0.076 \\
\hline Pachymetry $(\mu \mathrm{m})$ & $531 \pm 31(460$ to 625$)$ & $544 \pm 35(48 \mid$ to $63 \mathrm{I})$ & $6.42 \mathrm{E}-6$ \\
\hline
\end{tabular}

Note: Homoscedastic independent student $t$ test.

Abbreviations: D, diopters; MRSE, manifest refraction spherical equivalent; SD, standard deviation; $y$, years.

group with haze had best-corrected visual acuity of 20/20 or better.

\section{Intraocular pressure}

Significantly elevated postoperative intraocular pressure was defined as $\geq 25 \mathrm{mmHg}$ or as $\geq 10 \mathrm{mmHg}$ above preoperative intraocular pressure. At one month, more patients were noted to have elevated intraocular pressure in the fluorometholone group, although this difference was not statistically significant ( $P=0.26$, Chi-squared analysis), with a broad range of intraocular pressures measured $(24-46 \mathrm{mmHg})$. It is important to note that the fluorometholone group was on prednisolone four times a day during this time, whereas the loteprednol group had already been tapered to prednisolone twice daily. Subsequently, both groups had a lower incidence of elevated intraocular pressure $(P>0.05$ at months 2 and 3 , Fisher's exact test, Table 3).

\section{Visual acuity}

The mean uncorrected distance visual acuity ( $\log M A R)$ was $0.004 \pm 1.4(-0.30$ to 0.70$)$ in the fluorometholone group and $-0.028 \pm 1.1(-0.12$ to $0.40, P=0.013)$ in the loteprednol group (Table 4$)$. The mean postoperative corrected distance visual acuity ( $\log$ MAR) was $-0.06 \pm 0.85$ and $-0.07 \pm 0.81$ in the fluorometholone and loteprednol groups, respectively $(P=0.225)$. The MRSE at 6 months was $-0.08 \mathrm{D} \pm 0.54$ and $-0.10 \mathrm{D} \pm 0.31(P=0.582)$ in the fluorometholone and loteprednol groups, respectively. Seventy-nine percent and $77 \%$ of eyes in the fluorometholone and loteprednol groups achieved a postoperative uncorrected distance visual acuity

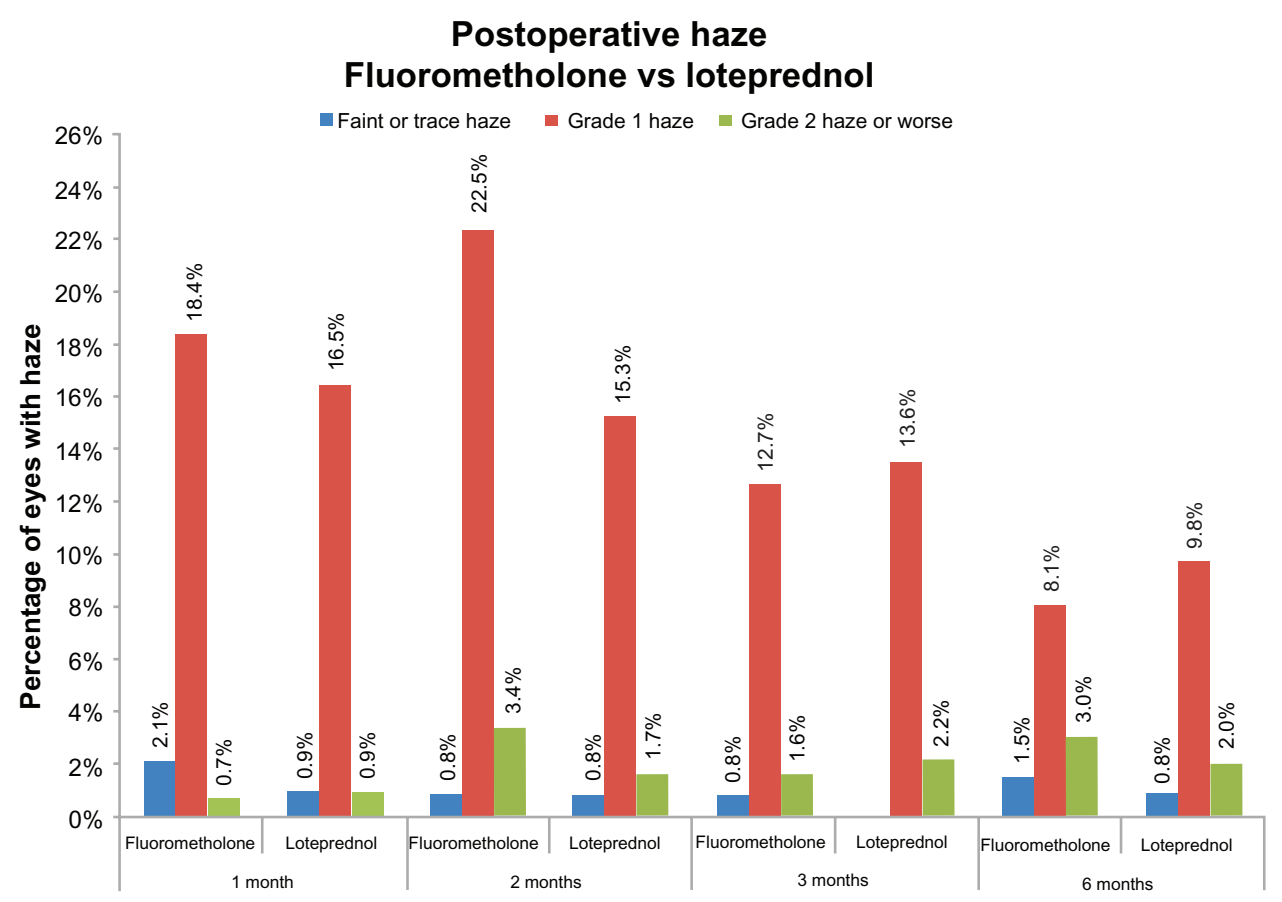

Figure I Percentage of eyes with haze at months I, 2, 3, and 6 postoperatively, comparing fluorometholone versus loteprednol. 


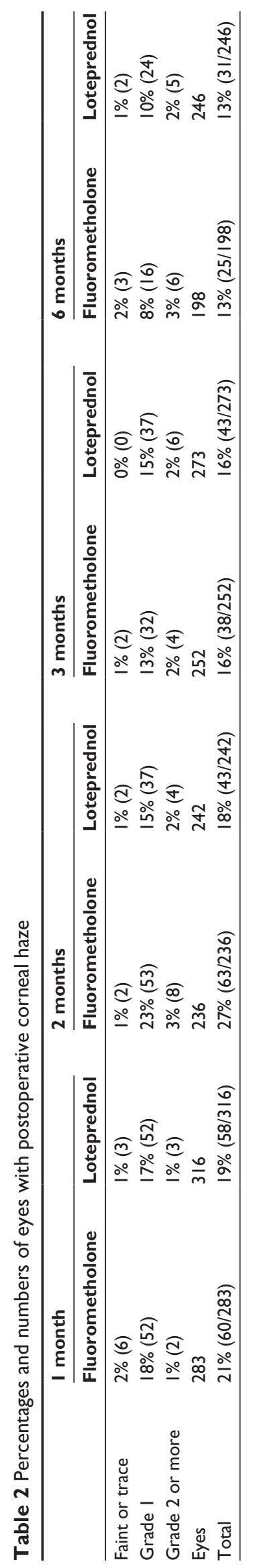

Table 3 Number of eyes with significant elevated intraocular pressure

\begin{tabular}{|c|c|c|}
\hline & Fluorometholone & Loteprednol \\
\hline \multicolumn{3}{|l|}{ I month } \\
\hline$>25 \mathrm{mmHg}$ or $10 \mathrm{mmHg}$ & I & I \\
\hline \multicolumn{3}{|l|}{ above preoperative IOP } \\
\hline IOP $25-30$ & 8 & 9 \\
\hline $1 O P>30$ & 5 & 0 \\
\hline Total & 14 & 10 \\
\hline IOP Range & 24 to 46 & 24 to 27 \\
\hline \multicolumn{3}{|l|}{2 months } \\
\hline$>25 \mathrm{mmHg}$ or $10 \mathrm{mmHg}$ & 1 & 3 \\
\hline \multicolumn{3}{|l|}{ above preoperative IOP } \\
\hline IOP $25-30$ & I & 0 \\
\hline $1 O P>30$ & 0 & 0 \\
\hline Total & 2 & 3 \\
\hline IOP Range & 22 to 26 & 17 to 24 \\
\hline \multicolumn{3}{|l|}{3 months } \\
\hline$>25 \mathrm{mmHg}$ or $10 \mathrm{mmHg}$ & 1 & 0 \\
\hline \multicolumn{3}{|l|}{ above preoperative IOP } \\
\hline IOP $25-30$ & 0 & 0 \\
\hline $1 O P>30$ & 0 & 0 \\
\hline Total & I & 0 \\
\hline IOP Range & 24 & N/A \\
\hline
\end{tabular}

Abbreviation: IOP, intraocular pressure.

of $20 / 20$ or better (Figure 2). Similar safety results were achieved in both groups, with $6 \%$ of eyes treated with fluorometholone losing 1 line of corrected distance visual acuity compared with $4 \%$ of eyes treated with loteprednol (Figure 3). Eighty-nine percent of fluorometholone eyes and $90 \%$ of loteprednol eyes achieved postoperative spherical equivalent refraction within $0.50 \mathrm{D}$ of plano (Figure 4).

\section{Discussion}

Loteprednol is approved for the treatment of inflammatory conditions of the anterior segment, including allergic conjunctivitis and anterior uveitis. ${ }^{8}$ Animal studies comparing loteprednol with dexamethasone, prednisolone, and fluorometholone report loteprednol to have a smaller effect on intraocular pressure, with effective anti-inflammatory effects. ${ }^{9} 10$ Clinical studies have demonstrated clinical efficacy for loteprednol, but not at the level of prednisolone. ${ }^{11}$ The chemical structure of loteprednol lacks a ketone group found in other corticosteroids to be associated with cataract formation. Thus, loteprednol may be less cataractogenic than other corticosteroids. ${ }^{11}$ Like many ophthalmic medications, it may be used off-label and has been used in postoperative management of cataract surgery with success. ${ }^{12}$ The lower side effect profile, including a reduced likelihood of increased intraocular pressure, has led to its use after penetrating keratoplasty. ${ }^{13}$ 
Table 4 Outcomes at 6 months postoperatively

\begin{tabular}{|c|c|c|c|}
\hline Demographics & Fluorometholone & Loteprednol & \\
\hline Patients (n) & 142 & 153 & \\
\hline Eyes $(n)$ & 266 & 291 & \\
\hline Male:female & $\mathrm{I}: \mathrm{I}$ & $1: 1$ & \\
\hline Postoperative outcomes & Mean \pm SD (range) & Mean \pm SD (range) & $P$-value \\
\hline MRSE (D) & $-0.08 \pm 0.54(-4.00$ to 1.50$)$ & $-0.10 \pm 0.31$ ( -1.25 to 1.00$)$ & 0.582 \\
\hline Sphere (D) & $-0.23 \pm 58(-5.00$ to 1.00$)$ & $-0.24 \pm 0.36(-1.50$ to 1.00$)$ & 0.753 \\
\hline Cylinder (D) & $0.31 \pm 0.35(0.00$ to 2.00$)$ & $0.29 \pm 0.36(0.00$ to 1.50$)$ & 0.616 \\
\hline UDVA (logMAR) & $0.004 \pm 1.4(-0.30$ to 0.70$)$ & $-0.028 \pm 1.1(-0.12$ to 0.40$)$ & 0.013 \\
\hline UDVA (snellen) & $20 / 20.2(20 / 10$ to $20 / 100)$ & $20 / 18.7$ (20/I5 to $20 / 50)$ & - \\
\hline CDVA (logMAR) & $-0.060 \pm 0.85(-0.30$ to 0.18$)$ & $-0.070 \pm 0.8 \mathrm{I}(-0.30$ to 0.40$)$ & 0.225 \\
\hline CDVA (snellen) & $20 / 17.4(20 / 10$ to $20 / 30)$ & $20 / 17.0$ (20/10 to $20 / 50)$ & - \\
\hline
\end{tabular}

Note: Homoscedastic independent student $t$ test.

Abbreviations: D, diopters; MRSE, manifest refraction spherical equivalent; $n$, number; SD, standard deviation; UDVA, uncorrected distance visual acuity; CDVA, corrected distance visual acuity.

Given the controversy associated with steroid use in photorefractive keratectomy patients, no standard regimen is accepted. However, three common methods are employed, ie, no steroid in the absence of haze, a short course starting at 4 times a day with a rapid taper over a month, and a long course tapered over 6 months. ${ }^{14}$ Early clinical work in evaluating steroid use in photorefractive keratectomy used corticosteroids such as dexamethasone ${ }^{15}$ or fluorometholone. ${ }^{1}$ Prednisolone acetate is typically used postoperatively as an initial anti-inflammatory agent, ${ }^{16}$ which is then switched to a less potent steroid to minimize side effects. Although the risk of increased intraocular pressure with fluorometholone is a third that with dexamethasone, ${ }^{17}$ increased intraocular pressure has still been observed with its use. ${ }^{18}$

The use of loteprednol has been considered a viable alternative to these other steroids in minimizing intraocular pressure spikes while still attempting to control postoperative

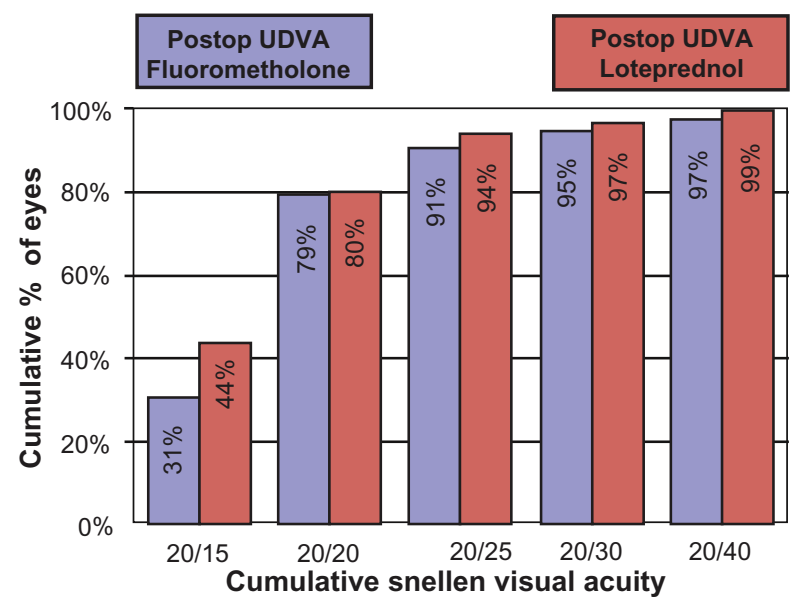

Figure 2 Uncorrected distance visual acuity represented for fluorometholone versus loteprednol at conclusion of study.

Abbreviation: UDVA, uncorrected distance visual acuity. inflammation and maintain a low incidence of haze. This retrospective study evaluates the outcomes of postoperative treatment with loteprednol and fluorometholone.

The two treatment groups were statistically similar for preoperative characteristics. The corrected postoperative visual outcomes were also similar between the two groups; however, the uncorrected distance visual acuity was statistically better in the loteprednol group (Figure 2, Table 4). Again, the retrospective nature of the study limits the ability to draw conclusions from this result, but at least noninferiority in the loteprednol group is suggested.

Secondary outcome variables in this study were incidence of haze and increase in intraocular pressure. The incidence of post-photorefractive keratectomy haze reported in the literature is low, although variable. The current study lacks sufficient power to delineate a statistical difference in treatment outcomes, given the low incidence of postphotorefractive

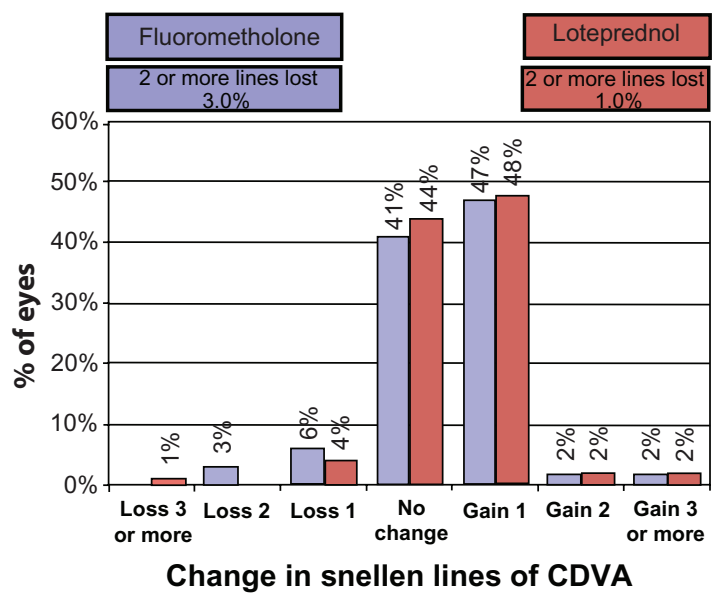

Figure 3 Change in corrected distance visual acuity over course of study for fluorometholone versus loteprednol.

Abbreviation: CDVA, corrected distance visual acuity. 


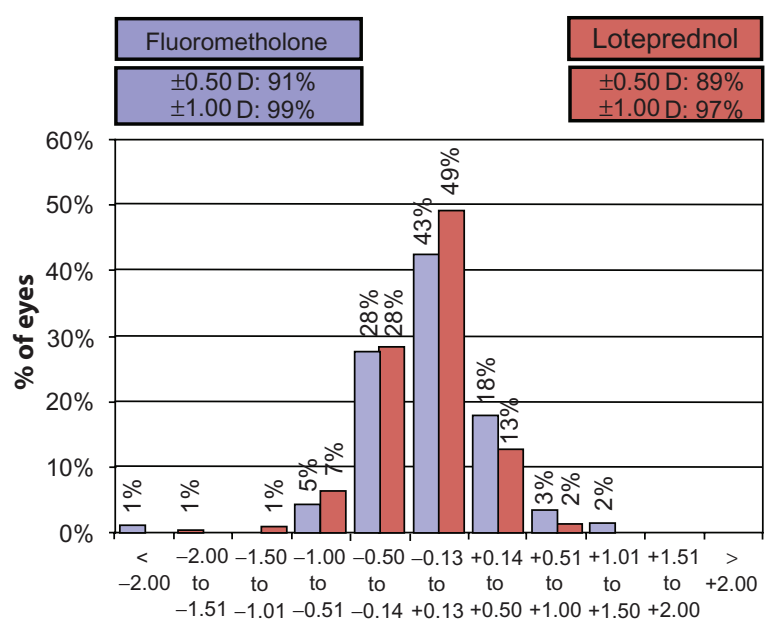

Postoperative spherical equivalent refraction (D)

Figure 4 Postoperative spherical equivalent refractive accuracy for fluorometholone versus loteprednol.

Abbreviation: D, diopters.

keratectomy haze. Even so, the incidence of haze was noted to be similar in the two groups throughout the postoperative period (Figure 1). More patients in the fluorometholone group $(32.6 \%)$ received treatment with mitomycin $\mathrm{C}$ than did those in the loteprednol group $(16.3 \%, P<0.001)$, and the duration of prophylactic treatment with topical steroid drops was longer in the fluorometholone group (16 weeks as compared with 12 weeks in the loteprednol group). Visible haze occurred at the same rate in both groups at 6 months $(13 \%$ fluorometholone, 13\% loteprednol). Future studies should match the use of mitomycin $\mathrm{C}$ and standardize the length of treatment to minimize confounding variables. Loteprednol prevented haze at least as well as fluorometholone, despite a shorter treatment time and less frequent use of mitomycin $\mathrm{C}$.

The steroid-induced intraocular pressure increase was similar in the two groups and is consistent with at least noninferiority of loteprednol as compared with fluorometholone. It is unclear whether a larger sample size would support previous studies, which have found a decreased intraocular pressure rise with use of loteprednol.,

An important consideration for the prescribing refractive surgeon is cost. Currently, fluorometholone $1 \%$ is available in a generic form but loteprednol is not. In surveying our local pharmacies, loteprednol is 3-6 times more expensive than generic fluorometholone. The potential benefits must be weighed against increased costs for patients and thirdparty payers.

At our academic institution, the relative number of laserassisted in situ keratomileusis (LASIK) procedures has decreased steadily over the last 5 years, while photorefractive keratectomy has increased, to the point of being more commonly performed than LASIK for the last 2 years. With this resurgence of photorefractive keratectomy, it is worthwhile to consider optimal postoperative management of these patients. While this research has some limitations due to its retrospective nature, it is the first study to report the efficacy and noninferiority of loteprednol prophylaxis after photorefractive keratectomy. Future prospective controlled studies could help determine whether loteprednol has true advantages over traditional topical steroids.

\section{Disclosure}

The authors report no conflicts of interest in this work.

\section{References}

1. O'Brart DP, Lohmann CP, Klonos G. The effects of topical corticosteroids and plasmin inhibitors on refractive outcome, haze, and visual performance after photorefractive keratectomy: a prospective, randomized, observer-masked study. Ophthalmology. 1994;101(9): $1565-1574$

2. Aras C, Ozdamar A, Aktunç R, Erçikan C. The effects of topical steroids on refractive outcome and corneal haze, thickness, and curvature after photorefractive keratectomy with a $6.0-\mathrm{mm}$ ablation diameter. Ophthalmic Surg Lasers. 1998;29(8):621-627.

3. Baek SH, Chang JH, Choi SY, Kim WJ, Lee JH. The effect of topical corticosteroids on refractive outcome and corneal haze after photorefractive keratectomy. J Refract Surg. 1997;13(7):644-652.

4. Vetrugno M, Maino A, Quaranta GM, Cardia L. The effect of early steroid treatment after PRK on clinical and refractive outcomes. Acta Ophthalmol Scand. 2001;79(1):23-27.

5. Noble S, Goa KL. Loteprednol etabonate: clinical potential in the management of ocular inflammation. Bio Drugs. 1998;10(4):329-339.

6. Holland EJ, Bartlett JD, Paterno MR, Usner DW, Comstock TL. Effects of loteprednol/tobramycin versus dexamethasone/tobramycin on intraocular pressure in healthy volunteers. Cornea. 2008;27(1):50-55.

7. Bartlett JD, Horwitz B, Laibovitz R, et al. Intraocular pressure response to loteprednol etabonate in known steroid responders. J Ocul Pharmacol. 1993;9(2):157-165.

8. Lotemax product insert. Available from: http://www.bausch.co.nz/ en_US/downloads/ecp/pharma/general/lotemaxinsert.pdf. Accessed May 21, 2011.

9. Howes JF, Baru H, Vered M, Neumann R. Loteprednol etabonate: comparison with other steroids in two models of intraocular inflammation. J Ocul Pharmacol. 1994;10(1):289-293.

10. Samudre SS, Lattanzio FA Jr, Williams PB, Sheppard JD Jr. Comparison of topical steroids for acute anterior uveitis. J Ocul Pharmacol Ther. 2004;20(6):533-547.

11. Loteprednol Etabonate US Uveitis Study Group. Controlled evaluation of loteprednol etabonate and prednisolone acetate in the treatment of acute anterior uveitis. Am J Ophthalmol. 1999;127(5):537-544.

12. Stewart R, Horwitz B, Howes J, Novack GD, Hart K. Double-masked, placebo-controlled evaluation of loteprednol etabonate $0.5 \%$ for postoperative inflammation. Loteprednol Etabonate Post-operative Inflammation Study Group 1. J Cataract Refract Surg. 1998;24(11): $1480-1489$.

13. Holland EJ, Djalilian AR, Sanderson JP. Attenuation of ocular hypertension with the use of topical loteprednol etabonate $0.5 \%$ in steroid responders after corneal transplantation. Cornea. 2009;28(10):1139-1143.

14. Stein R. Photorefractive keratectomy. Int Ophthalmol Clin. 2000;40(3): $35-56$. 
15. Garty DS, Kerr Muir MG, Lohmann CP, et al. The effect of topical corticosteroids on refractive outcome and corneal haze after photorefractive keratectomy: a prospective, randomized, double-blind trial. Arch Ophthalmol. 1992;110(7):944-952.

16. Corbett MC, O’Brart DP, Marshall J. Do topical steroids have a role following excimer laser photorefractive keratectomy? J Refract Surg. 1995;11(5):380-387.
17. Cantrill HL, Palmberg PF, Zink HA, Waltman SR, Podos SM, Becker B. Comparison of in vitro potency of corticosteroids with ability to raise intraocular pressure. Am J Ophthalmol. 1975;79(6):1012-1017.

18. Nagy ZZ, Szabó A, Krueger RR, Süveges I. Treatment of intraocular pressure elevation after photorefractive keratectomy. J Cataract Refract Surg. 2001;27(7):1018-1024.

\section{Publish your work in this journal}

Clinical Ophthalmology is an international, peer-reviewed journal covering all subspecialties within ophthalmology. Key topics include: Optometry; Visual science; Pharmacology and drug therapy in eye diseases; Basic Sciences; Primary and Secondary eye care; Patien Safety and Quality of Care Improvements. This journal is indexed on

Submit your manuscript here: http://www.dovepress.com/clinical-ophthalmology-journal

\section{Dovepress}

PubMed Central and CAS, and is the official journal of The Society of Clinical Ophthalmology (SCO). The manuscript management system is completely online and includes a very quick and fair peer-review system, which is all easy to use. Visit http://www.dovepress.com/ testimonials.php to read real quotes from published authors. 